\title{
Comparison of Leaf Disk, Greenhouse, and Field Screening Procedures for Evaluation of Grape Seedlings for Downy Mildew Resistance
}

\author{
Maurus V. Brown' ${ }^{1}$ and James N. Moore ${ }^{2}$ \\ Department of Horticulture, University of Arkansas, Fayetteville, AR 72701 \\ Patrick Fenn ${ }^{3}$ \\ Department of Plant Pathology, University of Arkansas, Fayetteville, AR 72701
}

Ronald W. McNew ${ }^{4}$

Agricultural Statistics Laboratory, University of Arkansas, Fayetteville, AR 72701

\section{Additional index words. Plasmopara viticola, disease resistance, inoculation, Vitis sp.}

Abstract. This research was conducted to compare an in vitro leaf disk technique with greenhouse and field evaluations for screening large populations of grape (Vitis $\mathbf{s p . )}$ seedlings for downy mildew (Plasmopara viticola Berk. \& Curt. Berl. \& de Toni) resistance. Seedlings produced by crossing resistant $x$ resistant, resistant $x$ susceptible, and susceptible $x$ susceptible parents were rated for sporulation, chlorosis, and necrosis. Leaf disk sporulation ratings at the first and second rating were highly correlated with the second sporulation rating in the field. Necrosis ratings from the leaf disk evaluations were significantly correlated with field necrosis ratings, but leaf disk chlorosis ratings were not correlated with field ratings. Some correlations, including evaluations of chlorosis, between the greenhouse and field ratings were highly significant. Seedling ratings of 0 or 1 for sporulation, chlorosis, and necrosis in the leaf disk assay agreed with field evaluations $\mathbf{8 5 . 6 \%}$ of the time vs. $80.3 \%$ agreement between greenhouse and field ratings. Sporulation was the parameter most highly correlated between leaf disk or greenhouse and field evaluation of resistance. The leaf disk procedure appeared to be a good predictor of field resistance, and is more practical than the greenhouse method for screening large populations.

Downy mildew is a devastating disease of grapes worldwide. Symptoms appear as yellowish, oily lesions on the adaxial leaf surface as a result of chlorophyll disruption, and as angular necrotic lesions that eventually coalesce into large necrotic areas. The characteristic signs of downy mildew are white sporangiophores and sporangia that emerge through the stomata (Emmett et al., 1992). Heavily mildewed leaves senesce, resulting in considerable defoliation. If there is no aggressive fungicide program to control downy mildew, overall vigor can be reduced, resulting in winter injury or even death of susceptible vines.

Given the economic importance of downy

Received for publication 3 Mar. 1998. Accepted for publication 30 Sept. 1998. Published with the approval of the Director, Arkansas Agricultural Experiment Station. The cost of publishing this paper was defrayed in part by the payment of page charges. Under postal regulations, this paper therefore must be hereby marked advertisement solely to indicate this fact.

${ }^{1}$ Former Graduate Student. Present address: Dept. of Horticulture and Crop Science, Ohio Agricultural Research and Development Center, Wooster, $\mathrm{OH}$ 44691.

${ }^{2}$ Distinguished Professor Emeritus.

${ }^{3}$ Associate Professor.

${ }^{4}$ Professor. mildew, grape breeders are developing more resistant cultivars and using different approaches to screen germplasm material and seedling populations. Germplasm has been evaluated in the field (e.g., Alleweldt, 1980; Becker and Zimmermann, 1978; Doazan, 1980; Eibach et al., 1989) in the greenhouse (e.g., Becker and Zimmermann, 1978; Denzer et al., 1995a, 1995b; Doazan and Kim, 1978), and in vitro with leaf disks (Denzer et al., 1995a, 1995b; Eibach et al., 1989; Staudt and Kassemeyer, 1995; Stein et al., 1985) and tissue culture (Barlass et al., 1986).

Field screening of seedling populations requires much land and time to complete evaluations. Greenhouse evaluations are used to screen for downy mildew resistance prior to establishing plants in a vineyard, but space, time, and maintenance of a proper environment conducive to disease development are concerns when evaluating large populations.

Leaf disks have provided an efficient, spacesaving in vitro approach for reproducing field responses in plants. Fungicides were evaluated by floating grape leaf disks inoculated with $P$. viticola on fungicide solutions in petri dishes (Herzog and Schuepp, 1985; Wicks and Hall, 1990). Inoculated leaf disks were used to make observations of $P$. viticola oospore development (Lehoczky, 1956) and the disease cycle (Denzer et al., 1995a, 1995b). Leaf disks have also been used to evaluate grape germplasm for downy mildew resistance (Eibach et al., 1989; Staudt and Kassemeyer, 1995; Stein et al., 1985).

This research was conducted to determine if a leaf disk technique could be used to screen large populations of grape seedlings for downy mildew resistance. Greenhouse screening was also compared with the leaf disk technique for accuracy in evaluating resistance.

\section{Materials and Methods}

Germplasm was obtained from the Univ. of Arkansas grape breeding program at the Univ. of Arkansas Fruit Substation, Clarksville, Ark. Plant material used as parents in crosses was chosen based on previous field evaluations of downy mildew resistance. The following crosses were made in 1995: Long John $\mathrm{x}$ A-1927 [Resistant (R) X Susceptible(S)], Long John X A-1581 (R X S), Ives X A-1927 (R X S), Ives X A-1581 (R X S), Buffalo x Moored (R X S), A-1702 $\times$ Buffalo (S $\times$ R), Buffalo $\times$ A$1702(\mathrm{R} \times \mathrm{S})$, Miss Blue $\times$ Buffalo $(\mathrm{R} \times \mathrm{R})$, Buffalo $x$ Miss Blue $(\mathrm{R} \times \mathrm{R}), \mathrm{A}-1702 \times$ Moored (SxS), Moored $\times$ A-1702 (S XS), and Midsouth $x$ Glenora $(\mathrm{R} x \mathrm{~S})$. Sixteen seedlings were selected and evaluated in 1996 from each population with the exception of Miss Blue $x$ Buffalo, which had only 12 seedlings. Including seedlings and parents, 198 genotypes were evaluated.

Seeds were germinated in the greenhouse at $20 \pm 2{ }^{\circ} \mathrm{C}$, and seedlings were transplanted to peat pots at the first or second true-leaf stage. Hardwood cuttings of parents were rooted and the plants were transplanted to peat pots. Plants were maintained in the greenhouse for the leaf disk and greenhouse screenings, and transplanted to the vineyard in May for field evaluations.

Leaf disk protocol. Four 16-mm-diameter disks were cut with a cork borer from one leaf of each of 20 greenhouse-grown grape cultivars with different levels of downy mildew resistance. These were placed abaxial surface up on water-saturated filter paper sheets laid over cellulose sponges in plastic containers $(8.9 \times 45.7 \times 30.5 \mathrm{~cm})$. A grid on the filter paper indicated the location of each leaf disk.

Inoculum was prepared by rinsing infected leaves from a greenhouse-grown susceptible selection with distilled water and adjusting to $5 \times 10^{4}$ sporangia/mL using a hemacytometer. A preliminary experiment indicated no differences in symptoms when $2 \times 10^{4}, 5 \times 10^{4}$, or 1 $\times 10^{5}$ sporangia/mL were used. An air brush sprayer was used to inoculate the leaf disks to the point of runoff, and no surfactant was used. Containers were closed and placed on shelves at $22 \pm 2{ }^{\circ} \mathrm{C}$ under cool-white fluorescent lamps (14 h-photoperiod, $\approx 70 \mu \mathrm{E} \cdot \mathrm{m}^{-2} \cdot \mathrm{s}^{-1}$ ) to promote infection and sporulation. Leaf disks were rated for sporulation, chlorosis, and necrosis independently on a scale of 0-5: $0=$ no sign, no symptoms; $1=>0$ to $10 \% ; 2=>10 \%$ to $30 \% ; 3=>30 \%$ to $60 \% ; 4=>60 \%$ to $80 \%$; $5=>80 \%$ of the disk area at 4 and $7 \mathrm{~d}$ after inoculation. 
The experimental design was a randomized complete block with four replications, and one leaf disk from each plant was used per block (container). Tap water was poured into each container to a depth of $2.5 \mathrm{~cm}$ to maintain high relative humidity $(\mathrm{RH})$.

Leaf disk evaluation. Seedlings and parents were placed on greenhouse benches in five rows $\approx 0.3 \mathrm{~m}$ apart within rows and $0.3 \mathrm{~m}$ between rows. A single plant of each parent was placed on each of four benches. All plants were completely randomized on each bench.

For leaf disk screening, fully expanded leaves were selected from the fourth to sixth node from the base, as leaves this age generally provide more reliable ratings than older leaves (Staudt and Kassemeyer, 1995; Stein et al., 1985). Four 16-mm-diameter disks were cut from noninoculated leaves and placed on filter paper sheets in plastic containers as outlined for the leaf disk protocol. One leaf disk from each plant was used per block. Leaf disks were inoculated, incubated, and rated for sporulation, chlorosis, and necrosis as described for the leaf disk protocol. The experimental design was a randomized complete block with four replications.

Greenhouse evaluation. The plants used for leaf disk evaluation were also used for greenhouse screening. One young, fully expanded leaf of each seedling and each parent was inoculated on the abaxial surface with $5 \times$ $10^{4}$ sporangia/mL, and no surfactant was used. Inoculum was prepared as in the leaf disk procedure. A cool mist humidifier was enclosed in a polyethylene tent on each table to maintain $100 \% \mathrm{RH}$ for $24 \mathrm{~h}$ to ensure infection. Mist tables were covered with clear polyethylene tents prior to inoculations of seedlings, and after inoculation the tents were closed immediately. After $24 \mathrm{~h}$, the tents were opened to allow the leaves to dry. One day later, the tents were again closed around the benches, and opened only to water the plants, until ratings were completed. Runoff water and transpiration kept the RH near 100\%. A shadecloth was used to reduce sunlight, and to provide a temperature $\left(\approx 21 \pm 2{ }^{\circ} \mathrm{C}\right)$ more conducive to infection and development of downy mildew. Daylength was $\approx 12 \mathrm{~h}$ and no supplemental lighting was used. Each inoculated leaf was rated on the same $0-5$ scale as the leaf disks. Ratings were made as described before; however, the plants did not show significant downy mildew until day 5 . The experimental design was a randomized complete block (bench) with four replications.

Field evaluation. Plants were acclimated to field conditions by reducing the greenhouse temperature, and were transplanted to a vineyard in May when night temperatures remained consistently above $10^{\circ} \mathrm{C}$. Seedlings and parents (one parent per block) were planted in a randomized complete block design, with four, one-plant replications at Fayetteville, Ark. Plants were placed $0.3 \mathrm{~m}$ apart within a row and $3.0 \mathrm{~m}$ between rows and trained to a high bilateral cordon system. The vineyard was drip irrigated on a regular basis to avoid drought stress. No fungicides or insecticides were applied.
Grape seedlings and parents were rated for downy mildew resistance based upon their exposure to natural field inoculum. Evaluations for sporulation, chlorosis, and necrosis were conducted using the same rating scale as for the leaf disk and greenhouse procedures. Plants were evaluated on 14 Aug. and 4 Sept. 1996.

Data analysis. Data was analyzed using SAS, with a general linear model (SAS Institute, 1996). Correlation analysis was used to determine if there were significant relationships between leaf disk, greenhouse, and field ratings.

\section{Results and Discussion}

Leafdisk evaluation. Leaf disk evaluations showed a wide range in downy mildew resistance among genotypes. Sporulation and necrosis ratings ranged from 0 to 5 and ratings for chlorosis were generally 0,1 , or 2 , with a few rated 3 in the second rating (data not shown). Plants were rated as resistant ( 0 or 1$)$, moderately resistant (2), susceptible (3), and highly susceptible (4 or 5), respectively.

Correlation coefficients $(r)$ for sporulation ratings for leaf disks vs. sporulation in the field ranged from 0.47 to $r=0.67$ (Table 1), all significant at $P \leq 0.01$. Sporulation ratings from the leaf disk procedure also showed good correlation with field chlorosis and necrosis ratings ( $r=0.46$ to $0.68 ; P \leq 0.01$ ). However, leaf disk chlorosis ratings were not highly correlated with field ratings of sporulation, chlorosis, or necrosis (Table 1). Leaf disks generally did not become chlorotic; thus chlorosis is not a reliable measure of downy mildew resistance in vitro. Similarly, necrosis ratings from leaf disks were not highly correlated with field necrosis ratings. Necrotic lesions were commonly observed on leaf disks of susceptible plant material by the second rating. This may account for the higher correlations between leaf disk necrosis at the second rating and the field ratings for each parameter.

Other workers (Denzeretal., 1995 a, 1995b; Eibach et al., 1989; Staudt and Kassemeyer, 1995; Stein et al., 1985) have conducted leaf disk evaluations in petri dishes to screen for downy mildew resistance, but on a limited amount of germplasm. Eibach et al. (1989) reported that leaf disk evaluations were significantly correlated with field results $(r=$ 0.98 , a value higher than those found in our study). To screen grape germplasm for downy mildew resistance, Staudt and Kassemeyer (1995) floated leaf disks on tap water rather than laying them on moist filter paper. Leaf disks appear to remain viable under both conditions. In several studies (e.g., Denzer et al., 1995a, 1995b; Eibach et al., 1989; Staudt and Kassemeyer, 1995; Stein et al., 1985), inoculum was pipetted onto the abaxial surface of the leaf disk, and resistance was evaluated on the inoculated areas. In the present study, the entire surface of the leaf disk was covered by applying inoculum (with no surfactant) with an air brush sprayer. This method dispersed inoculum over a wider area of tissue and helped to assure a more accurate assessment of resistance.

The leaf disk procedure provided a controlled environment for screening seedlings for resistance. Temperature $\left(20 \pm 2{ }^{\circ} \mathrm{C}\right)$ and RH $(\approx 100 \%)$ remained fairly constant during the experiment. Most of the leaf disks that were not susceptible to downy mildew remained fresh and green during the evaluation period, and cutting the leaf disks did not appear to cause any adverse physiological response. Contamination from other fungi (e.g., Rhizopus sp. and Alternaria sp.) was not observed.

Greenhouse evaluation. In the greenhouse trial, when plants were inspected $4 \mathrm{~d}$ after inoculation for symptoms of downy mildew development, only one seedling showed sporulation. On the fifth day, sporulation and chlorosis were evident on several plants and a few showed necrotic symptoms (data not shown). By $7 \mathrm{~d}$ after inoculation, sporulation, chlorosis, and necrosis had increased on all susceptible seedlings, while several seedlings still showed no downy mildew symptoms.

Correlations between greenhouse sporulation ratings and field ratings were significant for each of the parameters (Table 1), with $r$ values from 0.57 to 0.61 , and the second chlorosis rating from the greenhouse was significantly correlated with the first and second chlorosis ratings from the field. The second necrosis ratings from the greenhouse were correlated with some of the field ratings, but the $r$ values were low.

Sporulation, chlorosis, and necrosis ratings in the greenhouse and in leaf disk screenings were better correlated with field ratings for each parameter at the second than at the first rating. Downy mildew appeared on susceptible greenhouse plants or leaf disks $\approx 4-5$ $\mathrm{d}$ after inoculation. By the time of the second rating, sporulation, chlorosis, and necrosis were generally more developed, depending on each genotype's level of resistance. Ratings taken for each parameter at the second rating for greenhouse and leaf disk procedures may have provided a more accurate assessment of field resistance for each genotype.

Reports indicate that grape seedlings have been screened in the greenhouse for downy mildew resistance (Becker and Zimmermann, 1978; Denzer et al., 1995a, 1995b), but procedures were not well defined and information regarding comparisons between greenhouse screenings and field evaluations was limited. In the present study, screening for resistance in the greenhouse required more space and time to inoculate than did the leaf disk procedure. Although the greenhouse procedure could be used to screen for resistance, the number of seedlings that could be evaluated at any one time would be limited.

To further compare the screening procedures, evaluations of seedlings rated as 0 or 1 for sporulation, chlorosis, and necrosis in the leaf disk and greenhouse tests were compared for agreement with field ratings. Leaf disk ratings for all three parameters agreed with the field ratings $85.6 \%$ of the time. Only $5.3 \%$ of seedlings rated susceptible in the leaf disk 


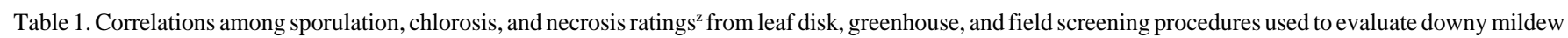
resistance in grape seedlings.

\begin{tabular}{|c|c|c|c|c|c|c|c|c|c|c|c|c|c|c|}
\hline \multirow[b]{3}{*}{ Field } & \multirow[b]{3}{*}{ Rating } & & \multicolumn{6}{|c|}{ Leaf disk } & \multicolumn{6}{|c|}{ Greenhouse } \\
\hline & & & \multicolumn{2}{|c|}{ Sporulation } & \multicolumn{2}{|c|}{ Chlorosis } & \multicolumn{2}{|c|}{ Necrosis } & \multicolumn{2}{|c|}{ Sporulation } & \multicolumn{2}{|c|}{ Chlorosis } & \multicolumn{2}{|c|}{ Necrosis } \\
\hline & & & 1 & 2 & 1 & 2 & 1 & 2 & 1 & 2 & 1 & 2 & 1 & 2 \\
\hline \multirow[t]{4}{*}{ Sporulation } & 1 & $r$ & $0.56^{y}$ & 0.67 & 0.14 & 0.32 & 0.03 & 0.44 & 0.61 & 0.64 & 0.06 & 0.41 & -0.03 & 0.23 \\
\hline & & $P$ & $<0.01$ & $<0.01$ & 0.05 & $<0.01$ & 0.72 & $<0.01$ & $<0.01$ & $<0.01$ & 0.37 & $<0.01$ & 0.69 & $<0.01$ \\
\hline & 2 & $r$ & 0.47 & 0.55 & 0.11 & 0.24 & 0.18 & 0.48 & 0.57 & 0.59 & 0.13 & 0.37 & 0.07 & 0.22 \\
\hline & & $P$ & $<0.01$ & $<0.01$ & 0.14 & $<0.01$ & 0.01 & $<0.01$ & $<0.01$ & $<0.01$ & 0.06 & $<0.01$ & 0.31 & $<0.01$ \\
\hline \multirow[t]{4}{*}{ Chlorosis } & 1 & $r$ & 0.56 & 0.68 & 0.15 & 0.32 & 0.04 & 0.45 & 0.60 & 0.63 & 0.07 & 0.41 & -0.02 & 0.24 \\
\hline & & $P$ & $<0.01$ & $<0.01$ & $<0.04$ & $<0.01$ & 0.56 & $<0.01$ & $<0.01$ & $<0.01$ & 0.32 & $<0.01$ & 0.76 & $<0.01$ \\
\hline & 2 & $r$ & 0.46 & 0.51 & 0.10 & 0.23 & 0.18 & 0.48 & 0.50 & 0.52 & 0.09 & 0.32 & 0.06 & 0.23 \\
\hline & & $P$ & $<0.01$ & $<0.01$ & 0.18 & $<0.01$ & 0.01 & $<0.01$ & $<0.01$ & $<0.01$ & 0.19 & $<0.01$ & 0.41 & $<0.01$ \\
\hline \multirow[t]{4}{*}{ Necrosis } & 1 & $r$ & 0.53 & 0.64 & 0.08 & 0.26 & 0.02 & 0.43 & 0.58 & 0.63 & 0.04 & 0.38 & -0.04 & 0.27 \\
\hline & & $P$ & $<0.01$ & $<0.01$ & 0.28 & $<0.01$ & 0.77 & $<0.01$ & $<0.01$ & $<0.01$ & 0.59 & $<0.01$ & 0.58 & $<0.01$ \\
\hline & 2 & $r$ & 0.46 & 0.51 & 0.19 & 0.29 & 0.16 & 0.42 & 0.43 & 0.45 & 0.10 & 0.26 & 0.04 & 0.20 \\
\hline & & $P$ & $<0.01$ & $<0.01$ & $<0.01$ & $<0.01$ & 0.11 & $<0.01$ & $<0.01$ & $<0.01$ & 0.17 & $<0.01$ & 0.55 & $<0.01$ \\
\hline
\end{tabular}

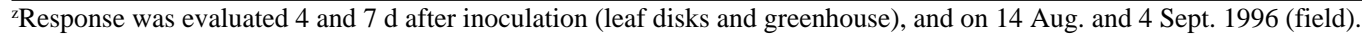

${ }^{\mathrm{y}} r$ values were determined using SAS with a general linear model.

assay appeared to be resistant in the field. Agreement between the greenhouse and field procedures was $80.3 \%$, and $6.2 \%$ of resistant seedlings would have been erroneously rated. In each screening procedure, many seedlings were accurately rated for resistance, which indicated that only a few seedlings would have been retained or discarded by mistake.

Results of this study indicate that both the leaf disk and greenhouse procedures could be used to screen grape seedlings for downy mildew resistance; however, the leaf disk method provides a more practical means of screening large seedling populations than does the greenhouse method. The sporulation ratings obtained from the leaf disk and greenhouse procedures were the best predictors of downy mildew resistance in the field. Because of the uniform exposure to inoculum and near optimum environmental conditions for downy mildew development in the leaf disk protocol, few susceptible seedlings will appear resistant using this protocol.

\section{Literature Cited}

Alleweldt, G. 1980. The breeding of fungus-resistant grapevine varieties, p. 242-250. In: Proc. Third Intl. Symp. on Grape Breeding. Dept.
Viticult. and Enol., Univ. of California, Davis. Barlass, M., R.M. Miller, and A.J. Antcliff. 1986. Development of methods for screening grapevines for resistance to infection by downy mildew. I. Dual culture in vitro. Amer. J. Enol. Viticult. 37:61-66.

Becker, N.J. and H. Zimmermann. 1978. Breeding of wine varieties resistant to downy mildew, $\mathrm{p}$. 209-214. In: Grapevine genetics and breeding, II Symp. Intl. sur l'Amelioration de la Vigne, Bordeaux, June 1977. Inst. Natl. Res. Agron., Paris.

Denzer, H., G. Staudt, and E. Schlosser. 1995a. Host settlement of Plasmopara viticola on different susceptible hosts. Vitis 34:45-49.

Denzer, H., G. Staudt, and E. Schlosser. 1995b. The behavior of Plasmopara viticola on resistant and susceptible grapevine varieties. Vitis 34:113-117.

Doazan, J.P. 1980. The selection of grapevine genotypes resistant to fungus diseases and their use under field conditions, p. 324-331. In: Proc. Third Intl. Symp. on Grape Breeding. Dept. of Viticult. and Enol., Univ. of California, Davis.

Doazan, J.P. and S.K. Kim. 1978. Recherche de génotypes résistants au mildou dans des croisements interspécifiques, p. 243-249. In: Grapevine genetics and breeding. II Symp. Intl. sur l'Amelioration de la Vigne, Bordeaux, June 1977. Inst. Natl. Res. Agron., Paris.

Eibach, R., H. Diehl, and G. Alleweldt. 1989.
Untersuchungen zur Vererbung von Resistenzeigenschaften bei Reben gegen Oidium tuckeri, Plasmopara viticola, und Botrytis cinerea. Vitis 28:209-228.

Emmett, R.W., T.J. Wicks, and P.A. Magarey. 1992. Downy mildew of grapes, p. 90-128. In: J. Kumar, H.S. Chaube, U.S. Singh, and A.N. Mukhopadhyay (eds.). Plant diseases of international importance, vol. III. Diseases of fruit crops. Prentice Hall, Englewood Cliffs, N.J.

Herzog, J. and H. Schuepp. 1985. Three types of sensitivity for metalaxyl in Plasmopara viticola. Phytopathol. Z. 114:90-93.

Lehoczky, J. 1956. Observations on oospore production by Plasmopara viticola in floating leaf discs in artificial culture. Vitis 5:17-19.

Patil, S.G., B.K. Honrao, V.G. Rao, and V.P. Patil. 1989. Evaluation of grape germplasm for downy mildew resistance and its significance in breeding. Indian J. Hort. 46:476-479.

SAS Institute. 1996. SAS ver. 6.12. SAS Inst., Cary, N.C.

Staudt, G. and H.H. Kassemeyer. 1995. Evaluation of downy mildew resistance in various accessions of wild Vitis species. Vitis 34:225-228.

Stein, U., C. Heintz, and R. Blaich. 1985. Die in vitro-prufung von Rebsorten auf Oidium- and Plasmopara-resistance.Z.PflKrankh.PflSchutz. 92:355-369.

Wicks, T. and B. Hall. 1990. Efficacy of dimethomorph (CME 151) against downy mildew of grapevines. Plant Dis. 74:114-116. 